\title{
Strategic management for logistics and supply chain operation in healthcare
}

\author{
I Syahrir ${ }^{1,2^{*}}$, Suparno ${ }^{1}$ and I Vanany ${ }^{1}$ \\ 1 Department of Industrial Engineering, Institut Teknologi Sepuluh Nopember, \\ Kampus ITS Sukolilo-Surabaya 60111, Indonesia \\ 2 Department of Engineering, Universitas Muhammadiyah Surabaya, Mulyorejo- \\ Surabaya 60113, Indonesia \\ *irwan.syahrir@ft.um-surabaya.ac.id
}

\begin{abstract}
In the healthcare industry, supply chain and logistics management are an important element in supporting the sustainability of the healthcare business. Business continuity in the healthcare industry requires improved quality of the healthcare sector. The quality of healthcare services may be affected by the performance of supply chain and logistics. Supply chain and logistics processes provide a substantial contribution in the overall financing of healthcare. The high costs incurred to finance the activities of the supply chain and logistics in the healthcare industry providing a major challenge for healthcare management. Management is demanded to achieve quality healthcare supply chain processes at a high level that minimize operating costs and improve service quality. So that, strategy and innovation in management are needed to achieve a high quality performance of supply chain and logistics in the healthcare industry in order to run effectively and efficiently. This paper discusses the research that focuses on the strategic management in the field of supply chain and logistics management in the healthcare industry. Based on obtained and selected articles will discuss various strategies and innovation within the healthcare system to improve supply chain performance.
\end{abstract}

Keywords: Supply Chain Management and Logistics, Healthcare Industry, Strategy and Innovation, Sustainability, and Healthcare Business

\section{Introduction}

Healthcare industry is one business sector that contributes a large economic in a country (1). In Indonesia on 2014, health financing contributes 2.8\% of GDP (Gross Domestic Product) about 24.9 billion US dollars (2). The growth of health financing in a country from year to year shows a considerable increase exceeding economic growth. The high cost of the health sector makes the healthcare industry a very important and strategic role. So the field of healthcare has become a rapidly growing research area in recent years (3). The unique characteristics and complexities of the healthcare system provide a significant challenge for researchers in the world to conduct further studies. The unique characteristic of the healthcare system is that it lies in the relation between the elements in the supply chain. A large number of supply chain distributions in the healthcare system add to the complexity of the relationships between their chains. Thus interactions, relationships, 
activities of creation and collaboration among network actors become increasingly important for healthcare providers (4).

One of the most difficult domains to overcome is the inherent complexity of healthcare. Healthcare has a variety of users and complex processes and interactions (5). Healthcare in the context of healthcare providers such as hospitals have a wide variety of supply chain chains in terms of quantities or types (medical equipment, pharmaceutical drugs and medical products, doctors, nurses, etc.). So that efforts to improve the performance supply chain on healthcare system become an important issue of interest to be discussed more deeply and widely. Various methods and methods have been introduced by researchers to improve supply chain performance on healthcare. Use of information technology (69), collaboration and integration between their chains (4), Good logistics management (10) and effective and efficient inventory management (11) are considered to improve supply chain healthcare performance.

Healthcare is a service industry that not only prioritizes service quality but also safety in providing patient care (12). According to (13) the topics discussed in the OM and SCM areas of the healthcare system are using information technology in services, operational strategies, service system design, service quality strategies and capacity planning, service process control and scheduling.

Improving the performance of healthcare services can also be done through collaboration and integration between supply chains. In (4) say that Value Co-Creation (VCC) creates healthcare in the context of the healthcare sector can be achieved through the concept of supply chain collaboration (SCC) Its components. Chen et al. (10) has conducted research to investigate factors affecting the performance of the hospital supply chain through trust, knowledge exchange, IT integration between the hospital and its suppliers (IT integration the hospital - its suppliers ), and hospital-supplier integration. According to (10), empirical results indicate that hospitals that have a high degree of logistics integration with suppliers will result in better performance in the supply chain.

Research in the field of healthcare supply chain will be the emphasis of issues to be discussed. In this paper, there will be discussed areas of research in the areas of logistics and supply chain.

\section{Healthcare logistic and Supply chain}

In the healthcare industry, logistics and supply chain management are considered an important aspect of healthcare management (14).The healthcare industry includes pharmaceutical manufacturers, healthcare providers (hospitals, clinics), distributors and pharmaceutical agents. The healthcare supply chain structure are represented by two types of healthcare industries, namely the pharmaceutical industry and healthcare providers. Chain distribution channels within the healthcare system are grouped into two paths, the external chain path and the internal chain path (Figure 1). The external chain consists of manufacturers, distributors and pharmaceutical agents. Healthcare providers represented hospitals or clinics that are providing health care for consumers/patients.

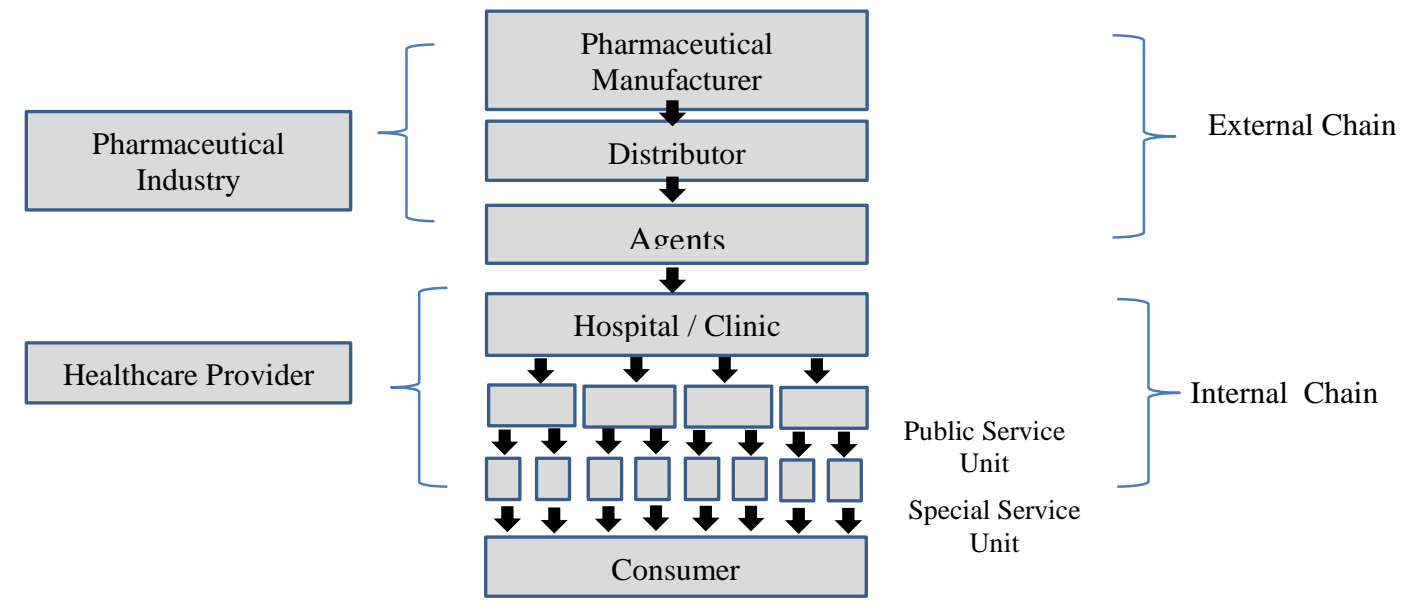

Figure 1. Healthcare Supply Chain Structure. 
The number of distribution channels within the supply chain healthcare structure requires healthcare management to manage supply chain performance effectively and efficiently, especially in the logistics department.Hospitals as one of the healthcare industries are a very important part of the health care system. The industrial sector that provides this health service is faced directly with consumers / patients. Hospitals in the healthcare system have a diverse supply chain structure and many distribution channels. The hospital has a public service unit that includes administration, emergency room, public clinic and others. Specialized service units within the hospital include medical laboratory, radiology room, inpatient room, public kitchen, drug depot and others. The complexity of relationships between the hospital's distribution channels lays in the independence of each distribution units in the internal chain system. The uniqueness of the distribution channels in the hospital are between service units has dependencies. A service unit will depend on the performance of other supply chain units. Improved service performance within each service unit will affect the performance. of hospital supply chain.

Good logistics and supply chain operations within the hospital can also affect the operational performance of health services. Hospital healthcare operations can be categorized under two conditions, namely regular and non-regular conditions. Regular conditions are health care operations under normal conditions. Non-regular operations are conditions where health-care operations experience supply chain disruptions due to extreme situations such as natural disasters, eg earthquakes, hurricanes, floods, volcanoes, epidemics, etc. Therefore, demand for healthcare can be categorized into two types, namely regular demand and non-regular demand (Figure 2). The characteristic of regular demand is deterministic because the daily operation of the hospital is still predictable needs. Non-regular demand has an uncertain and emergency nature because it is associated with an unpredictable natural disaster event.

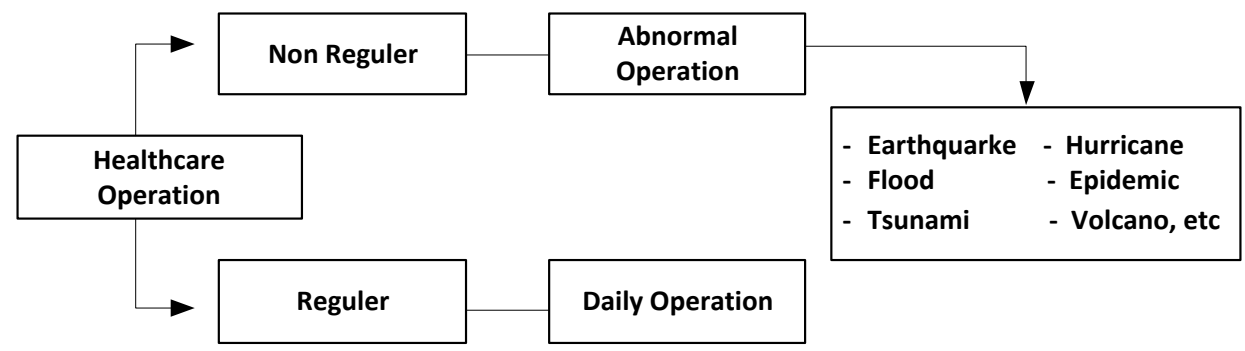

Figure 2. Demand Characteristics in healthcare.

Most of the research in the field of supply chain management and logistics are still considering the regular demand. There are still few researchers who consider non-regular demand such as the occurrence of natural disasters, such as (15) and (16). Mete \& Zabinsky (15) have proposed a stochastic optimization approach for storage and distribution of drugs to be used for various types and magnitude of disasters. Bashier \& Routray (16) developed a semi-quantitative risk assessment model in hospitals when faced with flood disasters. In (16) proposed that to reduce the low quality of health services is to meet every demand for medicines. From the description above, it can be said that the supply of medicines are one of the important parts in the supply chain operation of natural disaster management.

At the time of the disaster, usually, the need for medicines will increase the number of natural disaster victims increases. Healthcare inability to meet the needs of drugs will be dangerous to patients. Mohanty and Chakravarty (17) found uncertainty and imbalance between the number of patients and the availability of medicines in hospitals during epidemic disasters. These findings suggest the need for more serious attention to the supply of medical needs in situations of natural disasters, especially drugs. The inventory management of medicines in healthcare that is able to cope uncertainty and emergency in disaster event would becomes very important and strategic 


\section{Supply chain performance and logistics healthcare strategy.}

In general, hospitals emphasize reducing the cost of operating health services without reducing the quality of services. Hospital cost in healthcare supply chain had contributes $30 \%$ of the operational budget in hospital (18). Therefore, it becomes an opportunity and a management challenge to be able to make operational cost savings on health services in hospitals. Improved supply chain performance in the healthcare industry is considered to reduce operational costs.

Aptel \& Pourjalali (14) recommended that the healthcare industry uses a variety of new management methods to improve its operational performance. Hospital logistics management is an important part of the healthcare supply chain. The logistics department is responsible for procurement, receiving, inventory management, information systems, telemedicine, food service, transportation and inpatient services. Improved activities in the logistics department can lead to better service delivery and reduced health care costs. For example, if the inventory level of the hospital is low enough, it is necessary to reevaluate the ongoing inventory management. The development of new operational management is expected to increase the low inventory level. Reevaluation and redistribution of logistics functions to improve service improvements will have an impact on reducing medical inventory costs.

Narayana et al. (19) reported that the pharmaceutical industry is a major supporter of the healthcare sector. The effectiveness of pharmaceutical supply chain management is a crucial factor in the healthcare system. There are four important dimensions to consider in meeting the needs of healthcare services: availability of medicines, access to medicines (including access to medication and access to medical care), drug efficacy and drug safety (including administrative, consumption and environmental security). The ability of pharmaceutical supply chain management to integrate the four dimensional needs in the healthcare system will improve the efficiency and effectiveness of healthcare operations.

To improve the performance of logistics management and supply chain in healthcare may use information system integration through the use of information technology such as RFID $(9,20,21)$. Chong et al. (21) said that the implementation of information technology in healthcare provides many benefits such as cost reduction, error, and data integration of patients. Van der Togt et al. (22) explains that the use of RFID technology in the healthcare system positively impacts patient safety and security and concentrates the patient's logistics and medical products. The use of RFID in the reengineering process which includes purchasing, materials management, work practices and waste management can also reduce the cost of environmental damage and support the sustainability of the healthcare system (23). However, the commitment of leadership as one of critical success factors is needed to push the successful RFID implementation (24). Managerial and technological innovations can be used to plan and control quality, activity, and health services in the healthcare industry in both the private and public sectors. Kim et al. (25) said the use of technology in the healthcare system has become one of the innovations to overcome the challenges of chain complexity in order to achieve quality healthcare management.

Effective and efficient Inventory Management and Control can also improve the performance of the hospital supply chain $(26,27)$. Integration and collaboration between the chains in management operations can lead to improved supply chain performance in hospitals $(10,19,28)$. According to Bhakoo \& Singh (28), the application of collaborative arrangements between manufacturers and wholesalers/distributors will improve the practice of inventory management throughout the supply chain. To improve supply chain effectiveness can be achieved through collaboration between external partners and outsourcing strategy on purchasing, supply and inventory management, and transportation $(10,29)$. Chen et al. (10) investigate the effect of supply chain integration between hospitals and asset relationships (inter-organizational IT integration, trust and knowledge exchange). In (30) found that $28 \%$ of the ordering needs of the healthcare sector could not be delivered in accordance with the order due to limited stock limitations and unsuitable packaging sizes. This problem is caused by poor inventory control that impacts on transportation costs. 


\section{Conclusions}

Based on the results of the selected paper review above, strategies and innovations in supply chain and logistics management in healthcare are important factors in improving supply chain performance. Collaboration, integration, and coordination in management operations within the logistics work unit can reduce inefficiencies in supply chain processes. Improvements and performance improvements in logistics operational management can indirectly reduce the costs incurred in logistics operations. The use of information technology in the supply chain process provides more for the improvement of healthcare management quality. The information technology used in the healthcare process can improve the accuracy and speed of healthcare management decision making. Studies conducted show that the use of information technology in health care operations can reduce costs, avoid errors and integration of patient data. Good inventory management in health care can avoid the shortage of drugs.

Broader research in discussing various strategies and methods to improve supply chain healthcare performance can still be done. Increasing opportunities and challenges in supporting the development and sustainability of the healthcare industry will make this area more attractive. The rapid growth of the healthcare industry and the high economic cost in the health sector make this industry very important. Improving the quality of health services and reducing costs in healthcare operations is a key target of healthcare management. Therefore, effectiveness and efficiency in supply chain and logistics process become the demand of every healthcare industry. The field of operational management on logistics and supply chain processes in healthcare can be the direction of future research.

Research in the field of supply chain and logistics management not only focuses on the normal operating situation, but also need to consider the situation that is not normal like the occurrence of natural disasters. Supply chain and logistics management strategies in healthcare that focus on natural disaster situations can still be used as the next research direction. Healthcare management capabilities in dealing with uncertainty and emergency disaster situations are demands that must be met. So that supply chain and logistics management methods and strategies in healthcare more effective and efficient is still needed.

\section{References}

1. Fosso Wamba S, Anand A, Carter L. A literature review of RFID-enabled healthcare applications and issues. Int J Inf Manage. 2013 Oct 1;33(5):875-91.

2. World Health Organization. Global Health Expenditure Database. 2017.

3. Syahrir I, Suparno, Vanany I. Healthcare and Disaster Supply Chain: Literature Review and Future Research. Procedia Manuf. 2015 Jan 1;4:2-9.

4. Chakraborty S, Bhattacharya S, Dobrzykowski DD. Impact of Supply Chain Collaboration on Value Co-creation and Firm Performance: A Healthcare Service Sector Perspective. Procedia Econ Financ. 2014 Jan 1;11:676-94.

5. Isern D, Sánchez D, Moreno A. Agents applied in health care: A review. Int J Med Inform. 2010 Mar;79(3):145-66.

6. Caldeira Pedroso M, Zwicker R, Alexandre de Souza C. RFID adoption: framework and survey in large Brazilian companies. Ind Manag Data Syst. 2009 Aug 21;109(7):877-97.

7. Vanany I, Shaharoun AM. The Comprehensive Framework for RFID Justification in Healthcare. Int Bus Manag. 2011 Feb 1;5(2):76-84.

8. Maass W, Varshney U. Design and evaluation of Ubiquitous Information Systems and use in healthcare. Decis Support Syst. 2012 Dec 1;54(1):597-609.

9. Reyes PM, Li S, Visich JK. Accessing antecedents and outcomes of RFID implementation in health care. Int J Prod Econ. 2012 Mar 1;136(1):137-50.

10. Chen DQ, Preston DS, Xia W. Enhancing hospital supply chain performance: A relational view and empirical test. J Oper Manag. 2013 Sep 1;31(6):391-408.

11. Rachmania IN, Basri MH. Pharmaceutical inventory management issues in hospital supply chains. Management. 2013;3(1):1-5.

12. McFadden KL, Henagan SC, Gowen CR. The patient safety chain: Transformational 
leadership’s effect on patient safety culture, initiatives, and outcomes. J Oper Manag. 2009 Oct 1;27(5):390-404.

13. Dobrzykowski D, Saboori Deilami V, Kim S-C. A structured analysis of operations and supply chain management research in healthcare (1982-2011). Int J Prod Econ. 2014 Jan 1;147:51430.

14. Aptel O, Pourjalali H. Improving activities and decreasing costs of logistics in hospitals: a comparison of U.S. and French hospitals. Int J Account. 2001 Feb 1;36(1):65-90.

15. Mete HO, Zabinsky ZB. Stochastic optimization of medical supply location and distribution in disaster management. Int J Prod Econ. 2010 Jul 1;126(1):76-84.

16. Abbas HB, Routray JK. A semi-quantitative risk assessment model of primary health care service interruption during flood: Case study of Aroma locality, Kassala State of Sudan. Int J Disaster Risk Reduct. 2013 Dec 1;6:118-28.

17. Mohanty A, Chakravarty N. An epidemiological study of common drugs in the health supply chain. J Humanit Logist Supply Chain Manag. 2013 May 17;3(1):52-64.

18. Zepeda ED, Nyaga GN, Young GJ. Supply chain risk management and hospital inventory: Effects of system affiliation. J Oper Manag. 2016 May 1;44:30-47.

19. Narayana SA, Kumar Pati R, Vrat P. Managerial research on the pharmaceutical supply chain A critical review and some insights for future directions. J Purch Supply Manag. 2014 Mar $1 ; 20(1): 18-40$.

20. Çakıcı ÖE, Groenevelt H, Seidmann A. Using RFID for the management of pharmaceutical inventory - system optimization and shrinkage control. Decis Support Syst. 2011 Nov 1;51(4):842-52.

21. Yee-Loong Chong A, Liu MJ, Luo J, Keng-Boon O. Predicting RFID adoption in healthcare supply chain from the perspectives of users. Int J Prod Econ. 2015 Jan 1;159:66-75.

22. van der Togt R, Bakker PJM, Jaspers MWM. A framework for performance and data quality assessment of Radio Frequency IDentification (RFID) systems in health care settings. J Biomed Inform. 2011 Apr;44(2):372-83.

23. Kumar A, Rahman S. RFID-enabled process reengineering of closed-loop supply chains in the healthcare industry of Singapore. J Clean Prod. 2014 Dec 15;85:382-94.

24. Vanany I. An AHP Based Method to Prioritize the Barriers and Critical Success Factors of RFID Adoption in Healthcare. Int Bus Manag. 2011;5(6):427-35.

25. Kim RH, Gaukler GM, Lee CW. Improving healthcare quality: A technological and managerial innovation perspective. Technol Forecast Soc Change. 2016 Dec 1;113:373-8.

26. Dasaklis TK, Pappis CP, Rachaniotis NP. Epidemics control and logistics operations: A review. Int J Prod Econ. 2012 Oct 1;139(2):393-410.

27. Duan Q, Liao TW. Optimization of blood supply chain with shortened shelf lives and ABO compatibility. Int J Prod Econ. 2014 Jul 1;153:113-29.

28. Bhakoo V, Singh P, Sohal A. Collaborative management of inventory in Australian hospital supply chains: practices and issues. Supply Chain Manag An Int J. 2012 Mar 9;17(2):217-30.

29. Nicholson L, Vakharia AJ, Selcuk Erenguc S. Outsourcing inventory management decisions in healthcare: Models and application. Eur J Oper Res. 2004 Apr 1;154(1):271-90.

30. Haszlinna Mustaffa N, Potter A. Healthcare supply chain management in Malaysia: a case study. Supply Chain Manag An Int J. 2009 May 13;14(3):234-43. 